\title{
A novel recombinase polymerase amplification (RPA) assay for the rapid isothermal detection of Neospora caninum in aborted bovine fetuses
}

\author{
Ai-Ling Tian", Hany M. Elsheikhab, Dong-Hui Zhou ${ }^{\mathrm{c}, *}$, Yao-Dong Wu ${ }^{\mathrm{a}}$, Mu-Xin Chen ${ }^{\mathrm{d}}$, Meng \\ Wang $^{a}$, Dan Chen ${ }^{a}$, Xi-Chen Zhang ${ }^{\mathrm{e}}$ and Xing-Quan Zhu ${ }^{\mathrm{a}, *}$
}

${ }^{a}$ State Key Laboratory of Veterinary Etiological Biology, Key Laboratory of Veterinary Parasitology of Gansu Province, Lanzhou Veterinary Research Institute, Chinese Academy of Agricultural Sciences, Lanzhou, Gansu Province 730046, PR China

${ }^{\mathrm{b}}$ Faculty of Medicine and Health Sciences, School of Veterinary Medicine and Science, University of Nottingham, Sutton Bonington Campus, Loughborough, LE12 5RD, UK

${ }^{\mathrm{c}}$ Key Laboratory of Fujian-Taiwan Animal Pathogen Biology, College of Animal Sciences, Fujian Agriculture and Forestry University, Fuzhou, Fujian Province 350002, PR China

${ }^{\mathrm{d}}$ National Institute of Parasitic Diseases, Chinese Center for Disease Control and Prevention, Shanghai 200025, PR China

${ }^{\mathrm{e}}$ College of Veterinary Medicine, Jilin University, Changchun, Jilin Province 130062, PR China

\footnotetext{
* Corresponding authors:

Email addresses: donghui822002@163.com (D.-H. Zhou); xingquanzhu1@hotmail.com (X.-Q.Zhu)
} 


\section{ABSTRACT}

The development of a method to rapidly diagnose Neospora caninum infection is highly desirable. Recombinase polymerase amplification (RPA), combined with lateral flow (LF) strips, is a novel approach to rapidly amplify and visualize DNA. We have developed a prototype LF-RPA assay, using primers and a probe that targeted a specific sequence in the $N$. caninum NC-5 gene. The $N$. caninum-specific LF-RPA assay was first tested on purified DNA from oocysts and amplified $N$. caninum DNA to detectable levels in 10 minutes, at a constant temperature and without the need for an expensive thermocycler. The designed RPA primers and probe displayed $100 \%$ specificity for detecting N. caninum without any cross-reaction with DNA from nine related protozoan spp. (eg Toxoplasma gondii, Sarcocystis gigantean, Sarcocystis zuoi, Hammondia hammondi, Hammondia heydorni, Eimeria cylindrica, Plasmodium falciparum, Theileria annulata and Babesia bigemina). Although, LF-RPA assay detected amounts as low as $50 \mathrm{fg}$ of $N$. caninum DNA, it was nearly 5 -fold less sensitive than previously published $\mathrm{qPCR}$ and nested PCR assays. We tested the diagnostic performance of the LF-RPA assay for the detection of $N$. caninum DNA in aborted bovine fetal tissue samples, and compared the results with those obtained from nested PCR. Out of the 75 samples examined, 18 (24\%) and 17 (22.6\%) tested positive using LF-RPA and nested PCR, respectively. Our results indicate that LF-RPA is a suitable assay for the rapid and reliable detection of $N$. caninum.

\section{Keywords:}

Neospora caninum; Molecular diagnostics; Isothermal amplification; Recombinase polymerase amplification (RPA); Lateral flow (LF) strips 


\section{Introduction}

Neospora caninum is an obligate intracellular parasite that infects a wide range of both domestic and wild animals. Infection with this parasite is particularly important in cattle, as it can cause abortion, neonatal death and stillbirth (Dubey and Schares, 2011; Shaapan, 2016). The worldwide distribution of $N$. caninum has important economic consequences for the global cattle industry (Reichel et al., 2013). The lack of vaccines and effective drugs to combat neosporosis means that early detection of infected animals is important for therapeutic management and control.

A number of methods are used to diagnose abortions caused by $N$. caninum, including immunohistochemistry (IHC) (Uzêda et al., 2013), commercial indirect enzyme-linked immunosorbent assay (ELISA) kits (Dubey and Schares, 2006; Shukullari et al., 2015), indirect fluorescence antibody test (IFAT) (Dubey and Schares, 2006), and an agglutination test (Packham et al., 1998). These methods, although useful, have a number of limitations (reviewed in Sinnott et al., 2017). Molecular techniques to detect the presence of $N$. caninum genomic sequences are seen as potential diagnostic tools for the sensitive and early detection of infection. Real-time PCR (RT-PCR) and nested PCR are the two most commonly used methods for the detection of $N$. caninum genes (Masala et al., 2007; Ghalmi et al., 2008; Pereira et al., 2014; Yang et al., 2015; Qian et al., 2016). The requirement for a costly high-precision thermal cycler, laboratory-scale instrumentation and skilled staff to perform these analyses, have limited their use to well-equipped research laboratories. The advent of the isothermal nucleic acid amplification method, which does not require the need for specialized equipment, allows greater access to the nucleic acid amplification-based methods in geographic regions with limited technological and economic resources.

The recombinase polymerase amplification (RPA) assay is a new isothermal amplification method for the detection of nucleic acids of various infectious agents (Guimin et al., 2017; Hou et al., 2017; Lai et al., 2017; Kissenkötter et al., 2017). RPA does not require an initial denaturation of the DNA template. Instead, recombinase-primer complexes are used to scan double-stranded DNA and facilitate cognate strand exchange (Piepenburg et al., 2006). The RPA assay takes less than 20 min to perform, and requires a constant temperature within the range of $37{ }^{\circ} \mathrm{C}$ to $42{ }^{\circ} \mathrm{C}$ (Crannell et al., 2014; 
Lillis et al., 2014). Lateral flow (LF) strips are a simple tool used for diagnostic applications in resource-limited settings (Posthuma-Trumpie et al., 2009). By combining RPA with LF strips, a rapid system for detecting the target pathogen in biological samples can be developed. This method has been used for the detection of other parasitic agents, such as Plasmodium falciparum (Kersting et al., 2014); Giardia duodenalis (Crannell et al., 2015); Cryptosporidium spp. (Wu et al., 2016) and Theileria annulata (Yin et al., 2017). In the present study, we developed an isothermal LF-RPA assay for the detection of $N$. caninum infection in a diagnostic laboratory setting using fetal tissues obtained from recently-aborting cows.

\section{Materials and methods}

\subsection{Ethics statement}

This study was approved by the Animal Administration and Ethics Committee of Lanzhou Veterinary Research Institute, Chinese Academy of Agricultural Sciences, Lanzhou, PR China.

\subsection{Isolation of genomic DNA}

Total genomic DNA was extracted from $N$. caninum oocysts using a TIANamp Genomic DNA Kit, according to manufacturer's instructions (TIANGEN, Beijing, China). The quantity and purity of extracted DNA were assessed by measuring A260 and the ratio of A260/A280 on a Nanodrop ND-2000 spectrophotometer (Thermo Scientific, USA). The isolated genomic DNA of N. caninum was diluted in Tris-EDTA (TE) buffer.

\subsection{Primer and probe design}

The NC-5 gene of $N$. caninum (GenBank accession number X84238) was used as the target sequence (Yamage et al., 1996). NC-5-specific primers and a probe for the LF-RPA assay were 
designed according to the TwistDX guidelines, and the primer sequences were set to be identical, with the reverse primer labeled with biotin at the $5^{\prime}$ end. Several primers and probes were tested for their ability to detect the NC-5 gene using the TwistAmp ${ }^{\circledR}$ nfo kit (TwistDx, Cambridge, UK): only one primer-pair was eventually identified. The NC-5 specific primers and a probe for qPCR, and primers for nested PCR, were used as described previously (Pereira et al., 2014; Du et al., 2015). Primers and probes for LF-RPA, qPCR and nested PCR are listed in Table 1. All the oligonucleotides were produced by TaKaRa (Dalian, China).

\subsection{LF-RPA assay}

A $50 \mu 1$ reaction was performed using the TwistAmp ${ }^{\circledR}$ nfo kit. Each reaction contained $29.5 \mu 1$ rehydration buffer, $0.6 \mu \mathrm{l}$ TwistAmp ${ }^{\circledR}$ LF probe $(10 \mu \mathrm{M})$ which included a $3^{\prime}$ polymerase extension blocking group, an internal abasic site (tetrahydrofuran) and a 5' FAM, $2.1 \mu$ unlabeled forward primer $(10 \mu \mathrm{M}), 2.1 \mu \mathrm{l}$ biotin-labeled reverse primer $(10 \mu \mathrm{M}), 12.2 \mu \mathrm{l}$ deionized water and $1 \mu \mathrm{l} N$. canium genomic DNA. Approximately $2.5 \mu 1$ magnesium acetate $(\mathrm{MgAc})$ was added to the reaction to produce a RPA amplicon, which was then labelled with biotin and FAM, and detected using the LF strips. The tubes were then placed in an incubator block at $38{ }^{\circ} \mathrm{C}$ for $20 \mathrm{~min}$. Following amplification, $2 \mu \mathrm{l}$ of RPA products were diluted (1:50) in $98 \mu \mathrm{l}$ PBS containing Tween 20 (PBST) buffer. Commercially available Hybridetect-1 (MileniaBiotec GmbH, Gießen, Germany) strips were inserted vertically into the diluted products, and incubated for $5 \mathrm{~min}$. The positive detection of $N$. caninum was indicated on the LF strips by the presence of a colored test line. Separate control lines were used to confirm that the strip assay worked successfully.

\section{5. qPCR assay}

In order to compare the sensitivities of the LF-RPA assay and qPCR assay, the serially diluted $N$. caninum genomic DNA (at concentrations of $1 \mathrm{fg}, 10 \mathrm{fg}, 25 \mathrm{fg}, 50 \mathrm{fg}, 75 \mathrm{fg}, 10^{2} \mathrm{fg}, 10^{3} \mathrm{fg}, 10^{4} \mathrm{fg}, 10^{5}$ $\mathrm{fg}$, and $10^{6} \mathrm{fg}$ ) were used to evaluate the detection limit of the two assays. The qPCR amplification 
was performed in a $20-\mu 1$ reaction volume containing $10 \mu \mathrm{l}$ of SYBR Premix Ex Taq II (Ti RNaseH Plus) $(2 \times), 0.8 \mu \mathrm{l}$ of each PCR primer $(10 \mu \mathrm{M}), 0.4 \mu \mathrm{l}$ of ROX Reference Dye II (50×) (TaKaRa, Dalian, China), $6 \mu \mathrm{l}$ of $\mathrm{ddH}_{2} \mathrm{O}$, and $2 \mu \mathrm{l}$ of template DNA. The qPCR assay was conducted using the amplification settings of predenaturation at $95^{\circ} \mathrm{C}$ for $30 \mathrm{~s}$, followed by 40 cycles of denaturation at 95 ${ }^{\circ} \mathrm{C}$ for $5 \mathrm{~s}$ and annealing at $60{ }^{\circ} \mathrm{C}$ for $34 \mathrm{~s}$ on an ABI 7,500 Real-Time PCR System with 7,500 software v2.0 (Applied Biosystems, USA). Fluorescence readings were acquired using the SYBR Green I* chimeric fluorescence method. All assays were performed in triplicate.

\subsection{Nested PCR assay}

The nested PCR primers were used for the amplification of two fragments $(\sim 328 \mathrm{bp}$ [primary PCR] and 224 bp [secondary PCR]) of $N$. caninum NC-5 gene (Du et al., 2015). Primary PCR was performed in $12.5 \mu$ l Premix Taq (TaKaRa, Dalian, China), $0.5 \mu 1$ DNA templates, $1 \mu 1$ of each primer $(10 \mu \mathrm{M})$, and $10 \mu \mathrm{l} \mathrm{ddH}_{2} \mathrm{O}$. Sterile water was used in each test as a negative control. The primary thermal cycling conditions were: an initial denaturation step at $94{ }^{\circ} \mathrm{C}$ for 3 min followed by 35 cycles of $94{ }^{\circ} \mathrm{C}$ for $1 \mathrm{~min}, 53{ }^{\circ} \mathrm{C}$ for $1 \mathrm{~min}, 72^{\circ} \mathrm{C}$ for $2 \mathrm{~min}$ and a final extension step at $72{ }^{\circ} \mathrm{C}$ for $10 \mathrm{~min}$. As to the secondary PCR, the template included $0.5 \mu \mathrm{l}$ of the primary PCR product, and the cycling conditions were the same as those used in the primary PCR, with the exception that the annealing temperature was increased to $63{ }^{\circ} \mathrm{C}$. The amplified PCR product was detected by electrophoresis on $2 \%$ agarose gels containing $0.5 \mu \mathrm{g} / \mathrm{ml}$ ethidium bromide, followed by visualization under UV light.

\subsection{Optimization of LF-RPA conditions}

The amplification time and amplification temperature of the LF-RPA assay were two crucial parameters that we optimized in order to improve the efficiency of the assay for field applications. Different temperatures ranging from 15 to $50{ }^{\circ} \mathrm{C}$ were used to determine the optimal amplification temperature. After identifying the optimal temperature for the amplification reaction, the reaction was 
performed for $0,1,5,10,15,20,25$ and $30 \mathrm{~min}$ at $38{ }^{\circ} \mathrm{C}$ to determine the optimal reaction time. Reactions were stopped by putting the tubes into an ice box.

The analytical sensitivity of the LF-RPA assay, compared to that of qPCR and nested PCR, was evaluated under optimized conditions of amplification time and amplification temperature on serial dilutions of $N$. caninum DNA including $1 \mathrm{fg}, 10 \mathrm{fg}, 25 \mathrm{fg}, 50 \mathrm{fg}, 75 \mathrm{fg}, 10^{2} \mathrm{fg}, 10^{3} \mathrm{fg}, 10^{4} \mathrm{fg}, 10^{5} \mathrm{fg}$, and $10^{6} \mathrm{fg}$. Three reactions were performed for each DNA dilution in each assay. The specificity of the LF-RPA assay was evaluated using DNA extracted from nine related protozoan parasites, namely Toxoplasma gondii, Sarcocystis gigantean, Sarcocystis zuoi, Hammondia hammondi, Hammondia heydorni, Eimeria cylindrica, Plasmodium falciparum, Theileria annulata and Babesia bigemina. The extracted DNAs were previously validated by PCR and sequencing to confirm the specified parasite species.

\subsection{Validation of $L F-R P A$ for field application}

To determine the accuracy of the LF-RPA assay, results were compared with nested PCR results. Seventy-five tissue samples were collected from 75 separate aborted bovine fetuses from a domestic dairy farm in northwest China. Total genomic DNA was extracted from $30 \mathrm{mg}$ tissue of each tissue sample using the TIANamp Genomic DNA Kit (TIANGEN, Beijing, China). Isolated DNA was dissolved with $100 \mu \mathrm{l}$ of TE buffer and stored frozen at $-20{ }^{\circ} \mathrm{C}$. The extracted DNAs were analyzed using both LF-RPA and nested PCR.

\section{Results and discussion}

Traditionally, histopathological examination of $N$. caninum, together with serological assays and PCR-based assays (e.g. qPCR and nested PCR), have been the most common methods for $N$. caninum detection (Masala et al., 2007; Ghalmi et al., 2008; Pereira et al., 2014). These assays, while useful, are time-consuming and require expensive equipment, making them unsuited for use in resource-limited settings. In addition, no point-of-care $N$. caninum DNA test currently exists. We have 
developed and optimized the first rapid, sensitive and highly specific assay employing isothermal DNA amplification, using RPA and LF strips, for the detection of N. caninum in clinical samples.

\subsection{Optimization of amplification temperature}

The LF-RPA assay successfully amplified $N$. caninum DNA at a constant temperature between 30 and $45{ }^{\circ} \mathrm{C}$, providing a convenient assay to perform with a simple heating tool, such as a chemical heater or a battery-powered heater (Crannell et al., 2014; Lillis et al., 2014). The sharpness of the test bands varied according to the temperature used for the amplification reaction, indicating that temperature was a critical factor in the amplification efficiency (Fig. 1A). Clear bands were detected on strips from assays performed within a temperature range of 35 to $45{ }^{\circ} \mathrm{C}$. Test bands were either absent or less sharp outside of this range.

\subsection{Optimization of the reaction time}

The LF-RPA reaction time included both the RPA amplification and LF strips incubation periods. From the results obtained in section 3.1. (Fig. 1A), we performed RPA amplification at $38{ }^{\circ} \mathrm{C}$ for a period of either $1,5,10,15,20,25$ or $30 \mathrm{~min}$. The incubation time for LF strips was set at 5 min at ambient temperature. As shown in Fig. 1B, a faint test line appeared at $5 \mathrm{~min}$. The brightness of the bands increased as the amplification time increased. Although amplified DNA can be detected within 5 to $10 \mathrm{~min}$, we reckon that $10 \mathrm{~min}$ is the minimum amplification time that should be used to ensure the efficiency of the assay.

\subsection{Level of sensitivity}

The analytical sensitivity of LF-RPA, qPCR and nested PCR assays were determined, by testing panels of serial dilutions of $N$. caninum genomic DNA using the three assays. The LF-RPA assay had a detection limit of $\geq 50 \mathrm{fg}$ genomic DNA, shown by the reproducible presence of clear bands on the 
LF strips at DNA concentrations of $50 \mathrm{fg}, 75 \mathrm{fg}, 10^{2} \mathrm{fg}, 10^{3} \mathrm{fg}, 10^{4} \mathrm{fg}, 10^{5} \mathrm{fg}$, and $10^{6} \mathrm{fg}$ in the tested samples (Fig. 2A). Under the conditions used in our study, the LF-RPA assay demonstrated a higher sensitivity than both qPCR (2-fold increased sensitivity; Fig. 2B) and nested PCR (20-fold increased sensitivity; Fig. 2C). However, these results do not compare with those reported previously. For example, Collantes-Fernández et al., (2002) developed a real-time PCR based on NC-5 sequence, which was able to detect down to $10 \mathrm{fg}$ of genomic $N$. caninum DNA (ie., $\sim 5$-fold more sensitivity than LF-RPA). Likewise, Barratt et al., (2008) reported a detection limit of as low as $10^{-5} \mathrm{ng}(10 \mathrm{fg})$ of $N$. caninum by a nested PCR assay, which was also $\sim 5$-fold higher than that of LF-RPA developed in the present study. However, both PCR methods require highly trained staff and expensive laboratory-based thermocyclers, and the detection limit of nested PCR can vary substantially (Koivula et al., 2006) - due to the level of specificity of the gene target and stringency of the reaction condition (Innis and Gelfand 1990; Yang et al., 2016). Further validation studies from other settings are needed, in order to ensure that $N$. caninum isolates with different virulence and genetic structure, and from various hosts, are investigated.

\subsection{Specificity of the LF-RPA assay}

A major challenge to establish a $N$. caninum-specific detection assay results from the closely genetic relationship with other protozoan species (Sreekumar et al., 2003). The specificity of the LF-RPA assay was assessed via the amplification of DNA extracted from nine related protozoan species, namely T. gondii, S. gigantean, S. zuoi, H. hammondi, H. heydorni, E. cylindrica, P. falciparum, T. annulata and B. bigemina. No red-purple colored line was detected on the LF strips of the test line for any of these related species (Fig. 3), with the exception of N. caninum genomic DNA, indicating that the LF-RPA probe and primers were exclusively specific for the amplification of $N$. caninum DNA. The specific detection of other cattle-specific Sarcocystis spp. requires further investigation.

\subsection{LF-RPA performance using clinical samples compared with nested PCR}


Examination of aborted bovine fetal tissue samples in the present study showed that the LF-PRA method had a slightly higher sensitivity for detecting $N$. caninum in clinical specimens than nested PCR. Of the 75 aborted bovine fetal tissue samples examined, 17 (22.6\%) samples were detected by the nested PCR, whereas 18 (24\%) samples were detected by LF-RPA; representative results are shown in Fig. 4. As with the nested PCR result in Figure 2C, nested PCR detection levels in the tested aborted fetal tissue samples was also $>10^{2}$ fg DNA of $N$. caninum (Fig. 4B). The LF-RPA-based amplification products were sequenced, and all 18 obtained sequences confirmed that the LF-RPA assay had successfully amplified the NC-5 gene sequence from $N$. caninum. A previous TaqMan RT-PCR assay detected N. caninum DNA in 3 out of $5(60 \%)$ fetuses, born to heifers infected with $N$. caninum 60 days after artificial insemination (Pereira et al., 2014). Further study of a large number of specimens, with proven N. caninum infection, is required to confirm the suitability of our LF-RPA assay for clinical applications.

In this study, a new isothermal LF-RPA assay was developed for the accurate detection of $N$. caninum in clinical specimens. The assay showed high specificity, acceptable sensitivity and short turnaround time. Clear, easily visible bands appeared on the lateral flow strips, negating the need to use any specialized device. It is therefore possible to use the LF-RPA assay in resource-limited settings and replace or complement serological tests for the diagnosis of $N$. caninum infection. While this assay does not replace confirmatory laboratories tests, it could provide local animal care givers with timely relevant information, and help them to take appropriate decisions without having to wait for conventional PCR results (turnaround time: a few hours), serological testing (turnaround time: a few hours), or histopathological examination and phenotypic identification (turnaround time: a few days). Although might not be suitable as a pen-side test due to the possibility of cross contamination, this LF-RPA assay can be adapted as a single use consumable for use in non-laboratory settings where capital equipment, such as PCR thermocyclers are not available. Taken together, our results present LF-RPA as a novel, specific and sensitive method for the rapid detection of $N$. caninum in aborted bovine fetuses. 


\section{Acknowledgments}

Project support was provided by the Special Fund for Agro-scientific Research in the Public Interest (Grant No. 201303037), the National Key Basic Research Program (973 Program) of China (Grant No. 2015CB150300), the National Key Research and Development Program of China (Grant No. 2017YFD0501304), the National Key Project of Scientific and Technical Supporting Program (Grant No. 2012BAD12B07), and the Science and Technology Support Program of Gansu Province (Grant No. 1504NKCA054-6). We are thankful to Dr Luís Fernando Pita Gondim (Universidade Federal da Bahia, Brazil), Professor Jun-Jie Hu (Yunnan University, China) and Professor Ming Kang (Qinghai University, China) for providing DNA samples from Hammondia heydorni, Sarcocystis zuoi and Sarcocystis gigantea, respectively. We would also like to thank the reviewers for providing constructive and fair comments.

\section{References}

Barratt, J., Al Qassab, S., Reichel, M.P., Ellis, J.T., 2008. The development and evaluation of a nested PCR assay for detection of Neospora caninum and Hammondia heydorni in feral mouse tissues. Mol. Cell Probes. 22(4), 228-233.

Collantes-Fernández, E., Zaballos, A., Alvarez-García, G., Ortega-Mora, L.M., 2002. Quantitative detection of Neospora caninum in bovine aborted fetuses and experimentally infected mice by real-time PCR. J. Clin. Microbiol. 40(4), 1194-1198.

Crannell, Z.A., Cabada, M.M., Castellanosgonzalez, A., Irani, A., White, A.C., Richards-Kortum, R., 2015. Recombinase polymerase amplification-based assay to diagnose Giardia in stool samples. Am. J. Trop. Med. Hyg. 92, 583-587.

Crannell, Z.A., Rohrman, B., Richards-kortum, R., 2014. Equipment-Free incubation of recombinase polymerase amplification reactions using body heat. PLoS. One. 9, e112146. 
Du, L., Yang, D., Zhai, T., Gong, P., Zhang, X., Li, J., 2015. Detection of Neospora caninum-DNA in brain tissues from pigeons in Changchun, Jilin (China). Vet. Parasitol. 214, 171-173.

Dubey, J.P., Schares, G., 2006. Diagnosis of bovine neosporosis. Vet. Parasitol. 140, 1-34.

Dubey, J.P., Schares, G., 2011. Neosporosis in animals, the past five years. Vet. Parasitol. 180, 90-108.

Ghalmi, F., China, B., Kaidi, R., Daube, G., Losson, B., 2008. Detection of Neospora caninum in dog organs using real time PCR systems. Vet. Parasitol. 155, 161.

Guimin, Z., Hongmei, W., Peili, H., Chengqiang, H., Hongbin, H., 2018. Rapid and visual detection of Mycobacterium avium subsp. paratuberculosisby recombinase polymerase amplification combined with a lateral flow dipstick. J. Vet. Sci. 19(2), 242-250.

Hou, P., Zhao, G., Wang, H., He, C., Huan, Y., He, H., 2017. Development of a recombinase polymerase amplification combined with lateral-flow dipstick assay for detection of bovine ephemeral fever virus. Mol. Cell. Probes. pii: S0890-8508(17)30121-4.

Innis, M.A. and Gelfand, D.H., 1990. Optimization of PCRs.In PCR Protocols, A Guide to Methods and Applications, ed.Innis, M.A., Gelfand, D.H., Sninsky, J.J., White, T.J.pp. 3-12. San Diego: Academic Press, Inc.

Kersting, S., Rausch, V., Bier, FF., Von, N.M., 2014. Rapid detection of Plasmodium falciparum with isothermal recombinase polymerase amplification and lateral flow analysis. Malar. J. 13, 99.

Kissenkötter, J., Hansen, S., Böhlken-Fascher, S., Ademowo, O.G., Oyinloye, O.E., Bakarey, A.S., Dobler, G., Tappe, D., Patel, P., Czerny, C.P., Abd El Wahed, A., 2017. Development of a pan-rickettsial molecular diagnostic test based on recombinase polymerase amplification assay. Anal. Biochem. 544, 29-33.

Koivula, T.T., Juvonen, R., Haikara, A., Suihko, M.L., 2006. Characterization of the brewery spoilage bacterium Obesumbacterium proteus by automated ribotyping and development of PCR methods for its biotype 1. J. Appl. Microbiol. 100(2), 398-406.

Lai, M.Y., Ooi, C.H., Lau, Y.L., 2017. Recombinase polymerase amplification combined with a lateral flow strip for the detection of Plasmodium knowlesi. Am. J. Trop. Med. Hyg. doi: 10.4269/ajtmh.17-0738. [Epub ahead of print] 
Lillis, L., Lehman, D., Singhal, M.C., Cantera, J., Singleton, J., Labarre, P., Toyama, A., Piepenburg, O., Parker, M., Wood, R., Overbaugh, J., Boylei, D.S., 2014. Non-instrumented incubation of a recombinase polymerase amplification assay for the rapid and sensitive detection of proviral HIV-1 DNA. PLoS. One. 9, e108189.

Masala, G., Porcu, R., Daga, C., Denti, S., Canu, G., Patta, C., Tola, S., 2007. Detection of pathogens in ovine and caprine a bortion samples from Sardinia, Italy, by PCR. J. Vet. Diagn. Investing. 19, 96-98.

Packham, A.E., Sverlow, K.W., Conrad, P.A., Loomis, E.F., Rowe, J.D., Anderson, M.L., Marsh, A.E., Cray, C., Barr, B.C., 1998. A modified agglutination test for Neospora cainum: development, optimization, and comparison to the indirect flourescent-antibody test and enzyme-linked immunosorbent assay. Clin. Diagn. Lab. Immunol. 5, 467-473.

Pereira, G.R., Vogel, F.S., Bohrer, R.C., da Nóbrega, J.E., Ilha, G.F., da Rosa, P.R., Glanzner, W.G., Camillo, G., Braunig, P., de Oliveira, J.F., Gonçalves, P.B., 2014. Neospora caninum DNA detection by TaqMan real-time PCR assay in experimentally infected pregnant heifers. Vet. Parasitol. 99:129-135.

Piepenburg, O., Williams, C.H., Stemple, D.L., Armes, N.A., 2006. DNA detection using recombination proteins. PLoS. Biol. 4, 1115-1121.

Posthuma-Trumpie, G.A., Korf, J., van Amerongen, A., 2009. Lateral flow (immuno) assay: its strengths, weaknesses, opportunities and threats. A literature survey. Anal. Bioanal. Chem. 393, $569-582$.

Qian, W., Wang, T., Yan, W., Han, L., Zhai, K., Duan, B., Lv, C., 2016. Occurrence and first multilocus microsatellite genotyping of Neospora caninum from naturally infected dogs in dairy farms in Henan, Central China. Parasitol. Res. 115, 3267-3273.

Reichel, M.P., Ayanegui-Alcérreca, A., Gondim, L.E.P., Ellis, J., 2013. What is the global economic impact of Neospora caninum in cattle-the billion dollar question. Int. J. Parasitol. 43, 133-142.

Shaapan, R.M., 2016. The common zoonotic protozoal diseases causing abortion. J. Parasit. Dis. 40, 1116-1129. 
Shukullari, E., Hamel, D., Rapti, D., Pfister, K., Visser, M., Winter, R., Rehbein, S., 2015. Parasites and vector-borne diseases in client-owned dogs in Albania. Intestinal and pulmonary endoparasite infections. Parasitol. Res. 114, 4579-4590.

Sinnott, F.A., Monte, L.G., Collares, T.F., Silveira, R.M., Borsuk, S., 2017. Review on the immunological and molecular diagnosis of neosporosis (years 2011-2016). Vet. Parasitol. 239, $19-25$.

Sreekumar, C., Hill, D.E., Fournet, V.M., Rosenthal, B.M., Lindsay, D.S., Dubey, J.P., 2003. Detection of Hammondia heydorni-like organisms and their differentiation from Neospora caninum using random-amplified polymorphic DNA-polymerase chain reaction. J. Parasitol. 89(5), 1082-1085.

Uzêda, R.S., Schares, G., Ortega-Mora, L.M., Madruga, C.R., Aguado-Martinez, A., Corbellini, L.G., Driemeier, D., Gondim, L.F., 2013. Combination of monoclonal antibodies improves immunohistochemical diagnosis of Neospora caninum. Vet. Parasitol. 197, 477-486.

Wu, Y.D., Zhou, D.H., Zhang, L.X., Zheng, W.B., Ma, J.G., Wang, M., Zhu, X.Q., Xu, M.J., 2016. Recombinase polymerase amplification (RPA) combined with lateral flow (LF) strip for equipment-free detection of Cryptosporidium spp. oocysts in dairy cattle feces. Parasitol. Res. 115, 3551-3555.

Yamage, M., Flechtner, O., Gottstein, B., 1996. Neospora caninum: specific oligonucleotide primers for the detection of brain "cyst" DNA of experimentally infected nude mice by the polymerase chain reaction (PCR). J. Parasitol. 82, 272-279.

Yang, D., Liu, J., Hao, P., Wang, J., Lei, T., Shan, D., Liu, Q., 2015. MIC3, a novel cross-protective antigen expressed in Toxoplasma gondii and Neospora caninum. Parasitol. Res. 114, 3791-3799.

Yang, J., Liu, Z., Niu, Q., Liu, J., Xie, J., Chen, Q., Chen, Z., Guan, G., Liu, G., Luo, J., Yin, H., 2016. Evaluation of different nested PCRs for detection of Anaplasma phagocytophilum in ruminants and ticks. BMC Vet. Res. 12, 35.

Yin, F.Y., Liu, J.L., Liu, A.H., Li, Y.Q., Luo, J.X., Guan, G.Q., Yin, H., 2017. Rapid diagnosis of Theileria annulata by recombinase polymerase amplification combined with a lateral flow strip (LF-RPA) in epidemic regions. Vet. Parasitol. 237, 125-129. 


\section{Table 1}

Primers and probe used in the LF-RPA, qPCR and nested PCR to amplify $N$. caninum NC-5 gene sequence.

\begin{tabular}{lll}
\hline Assay type & Primer/probe Name & Sequence \\
\hline LF-RPA & F & 5'-TGGTAGCGGTGAGAGGTGGGATACGTGGTT-3' \\
& R & 5'-biotin-GCACTCGCCAGTCAACCTACGTCTTCTGCC-3' \\
& Probe & 5'-FAM-CGTCAGGGTGAGGACAGTGTGTCAATGATA-(TH \\
& & F)-TTATCGAGAGTTCAG-/C3-spacer/-3' \\
& F & 5'-TCCAATCCTGTAACGTGTTGCT-3' \\
qPCR & R & 5'-CACAAACAAAAAGGAGCCTTGCT-3' \\
Pereira et al. (2014) & 51 & 5'-CAGTCAACCTACGTCTTC-3' \\
Nested PCR & R1 & 5'-GTGCGTCCAATCCTGTAA-3' \\
Du et al. (2015) & F2 & 5'-GTTGCTCTGCTGACGTGTCGTTG-3' \\
& R2 & 5'-CTCAACACAGAACACTGAACTCTCG \\
\hline
\end{tabular}

Abbreviations: FAM, 6-Carboxyfluorescein; THF, tetrahydrofuran; F, forward primer; R, reverse primer. 
A

\section{Reaction temperature $\left({ }^{\circ} \mathrm{C}\right)$}

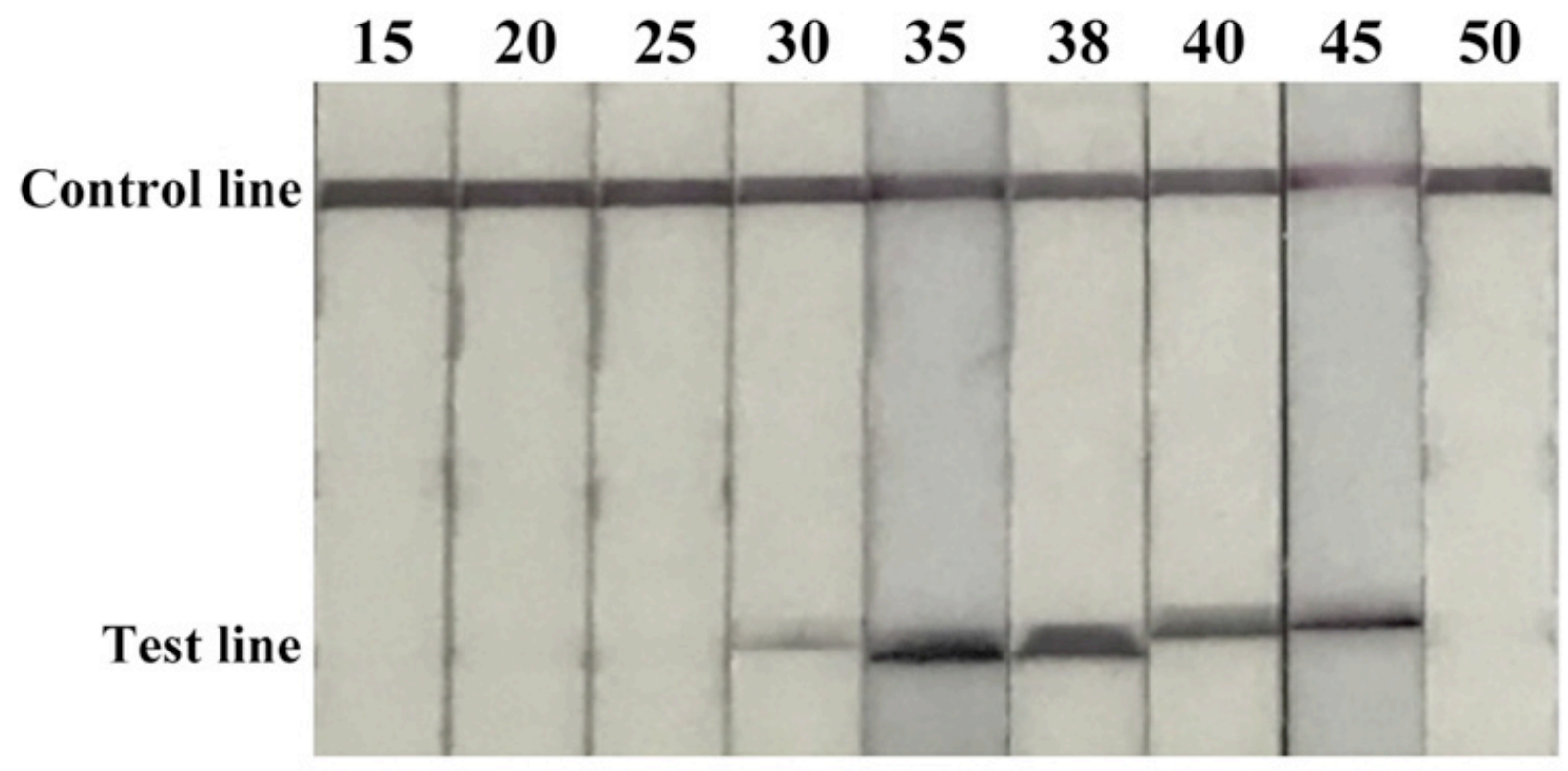

B

\section{Reaction time (min)}

\section{Control line}

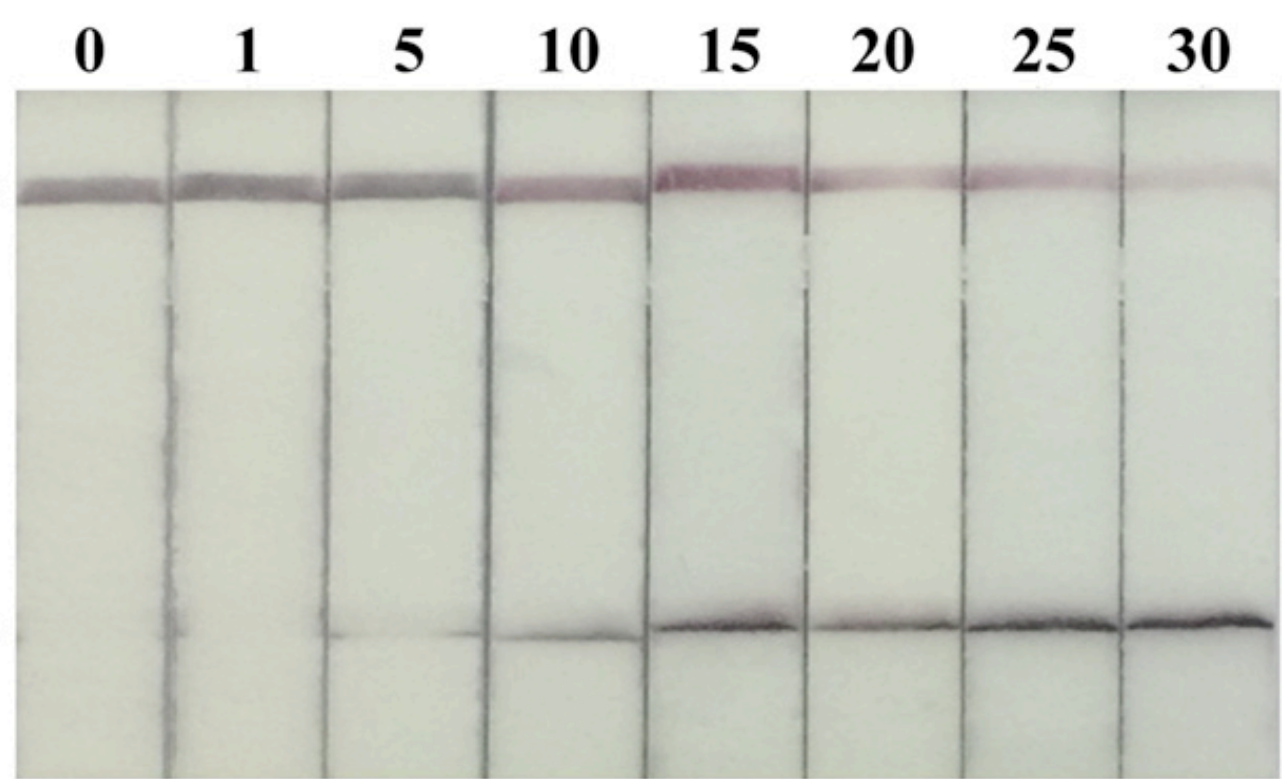

Fig. 1. Optimization of the amplification reaction temperature and time. (A) The LF-RPA assays were performed at different temperatures, as indicated in the figure. LF strips results were positive for reactions performed at constant temperatures - ranging from 30 to $45{ }^{\circ} \mathrm{C}$ - indicating that this assay can work well at a broad range of temperature environments. (B) After 5 min of isothermal amplification reaction, a faint test line was observed on the test strip. Stronger bands were observed on the LF strips after a longer amplification time. 


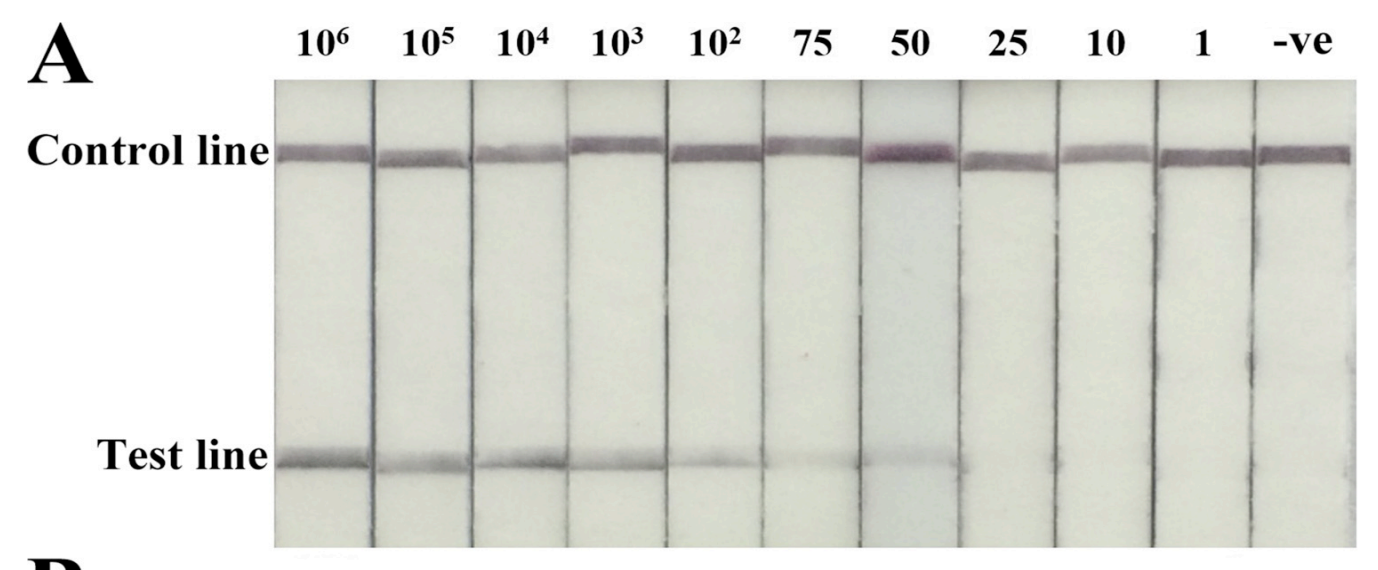

B
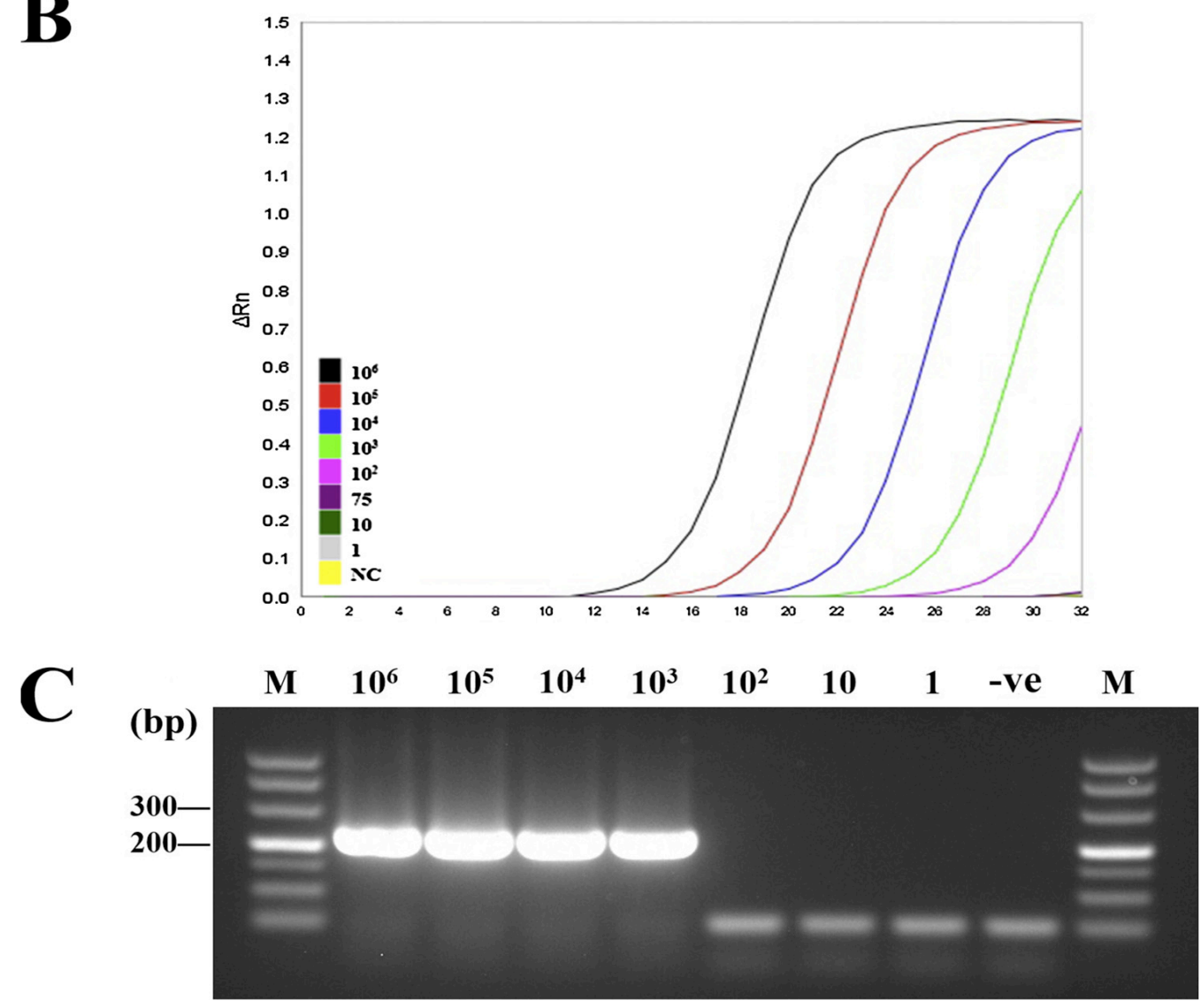

Fig. 2. Comparative sensitivities of LF-RPA, qPCR and nested PCR assays. Serial dilutions (1 fg, 10 $\mathrm{fg}, 25 \mathrm{fg}, 50 \mathrm{fg}, 75 \mathrm{fg}, 10^{2} \mathrm{fg}, 10^{3} \mathrm{fg}, 10^{4} \mathrm{fg}, 10^{5} \mathrm{fg}$, and $10^{6} \mathrm{fg}$ ) of $N$. caninum DNA were assessed using each of the three assays. Detection limits corresponding to $\geq 50 \mathrm{fg}$ (LF-RPA), $\geq 10^{2} \mathrm{fg}$ (qPCR) and $\geq 10^{3}$ fg (nested PCR) were obtained. Results show that (A) LF-RPA assay had a 2-fold increase in sensitivity when compared with qPCR assay (B), and a 20 -fold increase in sensitivity when compared with a nested PCR assay (C). Data from three replicates were consistent. Abbreviations: NC or -ve - negative control; M - DNA ladder. 


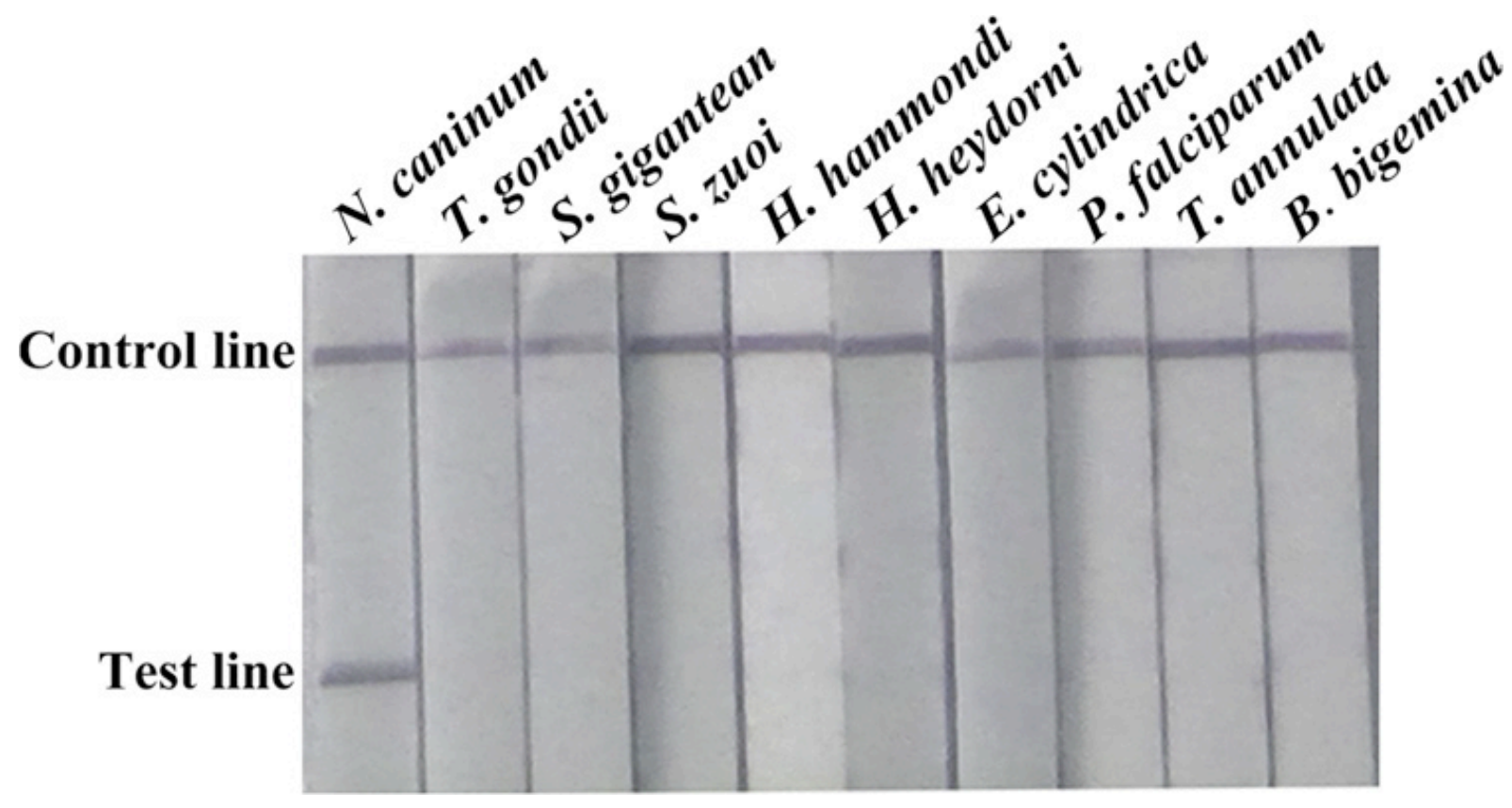

Fig. 3. Specificity of the LF-RPA assay. Genomic DNA was extracted from N. caninum and nine related parasite species: Toxoplasma gondii, Sarcocystis gigantean, Sarcocystis zuoi, Hammondia hammondi, Hammondia heydorni, Eimeria cylindrica, Plasmodium falciparum, Theileria annulata and Babesia bigemina. Amplification was obtained only when template DNA from N. caninum was used. Results from all nine related parasite species were negative. This lack of cross-reactivity with any of the DNA from these nine species closely-related to $N$. caninum, demonstrates the high degree of specificity of the LF-RPA assay. 
A

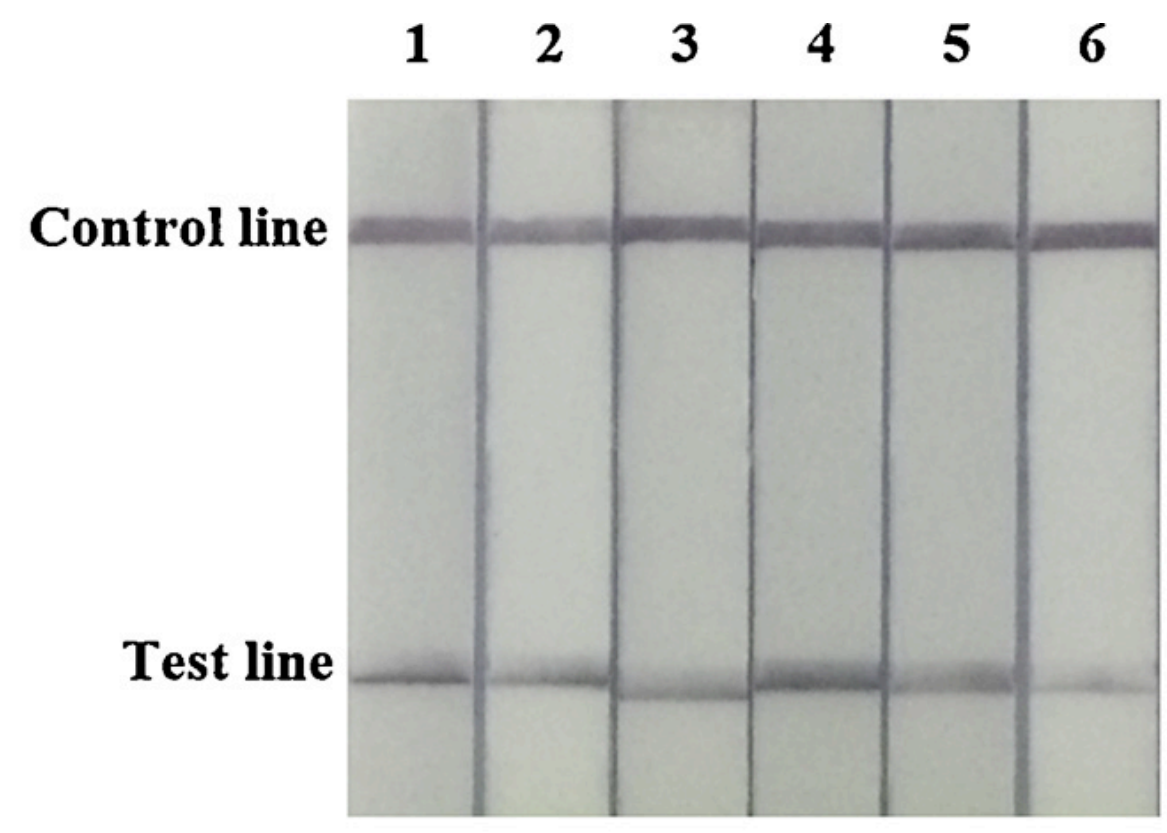

B

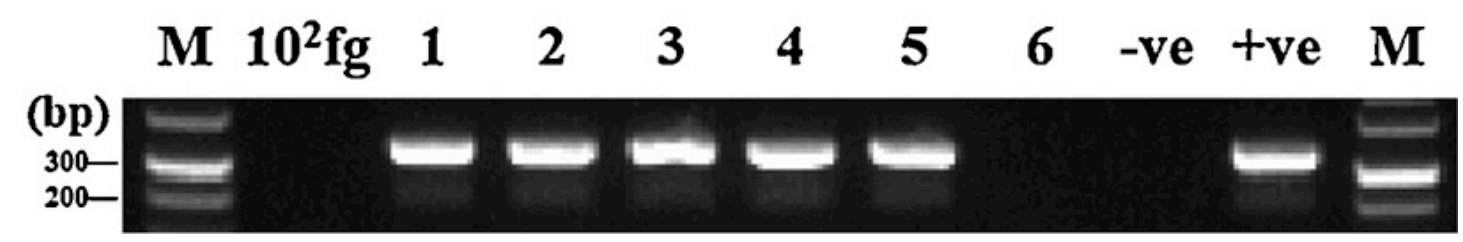

Fig. 4. Detection of representative aborted bovine fetal tissue samples by LF-RPA and nested PCR. Lanes 1-6 show representatives of the tested samples. (A) Six out of six bovine fetal tissue samples tested positive using LF-RPA assay. (B) Five out of six samples tested positive using nested PCR assay. Lanes 1-5 were positive, whereas negative control and lane 6 were negative. Abbreviations: M, DNA ladder; -ve, negative control; +ve, positive control. 